\title{
The Small Air Objects Detection Method on the Basis of Combination of Single-position and Different Receipt of Signals
}

\author{
Hennadii Khudov ${ }^{1}$, Andrii Lykianchykov ${ }^{2}$, Dmitry Okipniak ${ }^{3}$, \\ Oleksii Baranik ${ }^{4}$, Oleksii Ovcharenko ${ }^{5}$, Nazar Shamrai ${ }^{6}$ \\ ${ }^{, 1}$ Department of Radar Troops Tactic, Ivan Kozhedub Kharkiv National Air Force University, Kharkiv, Ukraine, \\ 2345kh_hg@ukr.net \\ ${ }^{2}$ Air Force Scientific Center, Ivan Kozhedub Kharkiv National Air Force University, Kharkiv, Ukraine, \\ rhudov@gmail.com \\ ${ }^{3}$ Department of Tactics of Combat (Operational) Support Units, Hetman Petro Sahaidachnyi National Army \\ Academy, Lviv, Ukraine, dmitry.okipniak@gmail.com \\ ${ }^{4}$ Department of Aviation Armament Complexes, Ivan Kozhedub Kharkiv National Air Force University, Kharkiv, \\ Ukraine, kozaktur@i.ua \\ ${ }^{5}$ Department of Anti-aircraft Missiles Tactic, Ivan Kozhedub Kharkiv National Air Force University, Kharkiv, \\ Ukraine, akeksey141177@gmail.com \\ ${ }^{6}$ Department of Tactic and Military Disciplines, Ivan Kozhedub Kharkiv National Air Force University, Kharkiv, \\ Ukraine, samrajnazar46@gmail.com
}

\begin{abstract}
An approach to increase the efficiency of detection of small air objects through the using of multi-position reception methods, in particular, the combination of single-position and spaced signal reception methods. The block diagram of the processing channels of the survey radar station of the meter range based on the combination of methods of single-position and spaced signal reception is given.
\end{abstract}

Key words : small air object, detection, method, single-position, signal, combination of methods.

\section{INTRODUCTION}

In modern conditions, the solution of the problem of building a reliable air defense system is significantly complicated due to the emergence of small unmanned aerial vehicles [1]-[6]. Small air objects such as guided missiles (projectiles), guided aerial bombs, cruise missiles of various types of bases, anti-radar missiles, unmanned aerial vehicles have specific flight characteristics [2]-[4], [7]-[11]. First of all, these are their small effective scattering surfaces, a wide range of speeds, the implementation of covert flights at low and very low altitudes using the terrain [2]-[4], [12]-[14]. These features significantly complicate the task of detecting small air objects.

\subsection{Problem analysis}

It is known that to increase the efficiency of radar reconnaissance of small air objects, a number of organizational and technical measures are used, which are summarized in [15]-[17]:

- the compaction of the location of radar stations in dangerous directions (creation of detection bands of low-altitude and small-sized objects);

- the using of radars of all frequency bands;

- the using of radars with the best capabilities (greatest energy potential), etc.

In [18]-[21] alternative ways to improve the quality of detection of small air objects are considered:

- the using of energies of external radiation sources;

- the using of the property of increasing the effective scattering surface in the resonant reflection of electromagnetic waves from the target;

- the using of the properties of increasing the bistatic effective scattering surface of the secondary radiation in comparison with the effective scattering surface of the inverse secondary radiation.

The main disadvantages inherent in these alternative methods of detecting small air objects are noted in [9], [22].

In [9] [22]-[24], to increase the detection efficiency of small air objects, the possibility of increasing the effective scattering surface of small objects in survey radars by using the properties of the bistatic effective scattering surface of the object with spaced reception of signals from external radiation sources. This becomes possible by supplementing (or introducing) into existing single-position surveillance radars additional modes of spaced reception. 
According to the results of research [9], [22]-[23] on the comparison of the bistatic and monostatic effective scattering surface of air objects, it was found:

- at values of bistatic angles less than 136 degrees, the value of the bistatic effective scattering surface does not exceed, and in some cases less than 2-5 dB, the values of the monostatic effective scattering surface, which leads to deterioration of radar detection capabilities of air objects;

- at values of bistatic angles close to 180 degrees, the value of the bistatic effective scattering surface significantly exceeds the value of the monostatic effective scattering surface (up to $30 \mathrm{~dB}$ ), which improves the radar's ability to detect small air objects;

- the sharpness of the bistatic scattering diagram is less than the sharpness of the monostatic scattering diagram, which reduces the flicker (noise) of the object and reduces its impact on the measurement errors of the object;

- for objects that are made by "Stealth" technology, there is an increase in the values of the bistatic effective scattering surface compared to the monostatic effective scattering surface.

\section{MAIN MATERIAL}

To ensure continuous radar control of flights of air objects at low altitudes, it is possible to use spaced radar systems that using radiation from external transmitters [9].

The multi-position spaced radar system of semi-active location in the field of radiation of the system of cellular communication, radio and television broadcasting of ground and space base is shown in Figure 1.

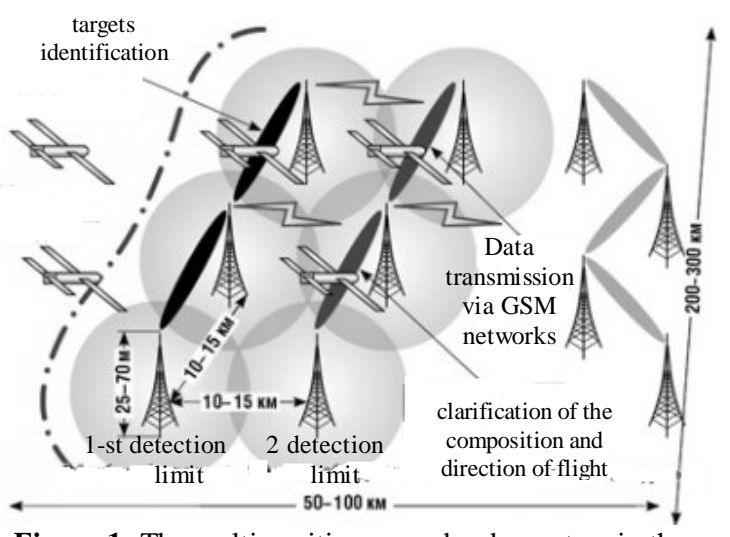

Figure 1: The multi-position spaced radar system in the radiation field of a cellular communication system
The system is built at several detection boundaries to a depth of 50-100 km along the front in the band 200-300 $\mathrm{km}$ and at an altitude of up to $1500 \mathrm{~m}$.

The vertical profile of the detection zone in the radiation field of the cell communication system is shown in Figure 2.

Each detection boundary represents a sequence of detection zones located between base stations (BS). The detection zone is formed by a single-base spaced (bistatic) Doppler radar. Information from each detection zone is sent via GSM networks to the Information Collection and Processing Center, which can be located many kilometers from the detection system. The objects are identified by direction-finding, frequency and time features, as well as by the installation of video recorders - by the image of objects.

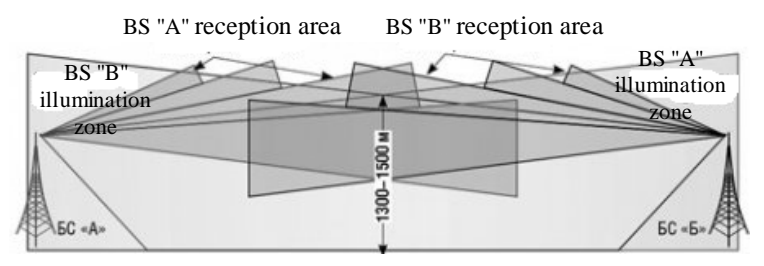

Figure 2: The vertical profile of the detection zone in the radiation field of the cell communication system

To solve the problem of detecting an air object while using the properties of its bistatic and monostatic effective scattering surface, it is necessary to ensure the implementation of the radar algorithm for detecting the object when it is irradiated by several transmitters. To do this, the radar must implement the appropriate channels for processing echo signals:

- the processing channel of echo signals that are reflected from the object when it is irradiated by a transmitter that is combined with a receiving device (provides the use of the properties of a monostatic effective scattering surface);

- the processing channels of echo signals, which are reflected from the object when it is irradiated by transmitters, which are spaced in space (provides the use of the properties of the bitastic effective scattering surface).

In general, you can use several independent transmitters that are spaced apart and irradiate the object. To process echo signals caused by the radiation of the corresponding transmitter, a separate processing channel must be implemented at the receiving point. Signals emitted by space-spaced transmitters can generally be incoherent. Therefore, the fluctuations of echo signals that are reflected from the object in monostatic and bistatic modes can also be considered independent. 
Based on the above, the algorithm for detecting an object when irradiated by several transmitters should be based on the principle of incoherent summation of the results of coordinated processing of echoes reflected by the target. The corresponding detection theory has been developed for multi-position systems, multi-channel systems, multi-frequency signal processing systems, etc. [9], [22]-[23].

The algorithm of optimal processing, which is based on the principle of incoherent summation of the results of coordinated processing of the corresponding echo signals, has the form (1)-(2) :

$$
\begin{aligned}
& \mathrm{L}_{1}=\sum_{\mathrm{i}=1}^{\mathrm{m}} \frac{\mathrm{A}_{\mathrm{i} 1}^{2}}{\mathrm{~N}_{\mathrm{i}}^{2}}\left|\tilde{\mathrm{Z}}_{\mathrm{i}}\right|^{2}, \\
& \mathrm{~L}_{1}=\sum_{\mathrm{i}=1}^{\mathrm{m}} \frac{\mathrm{A}_{\mathrm{i} 1}^{2}}{\mathrm{~N}_{\mathrm{i}}^{2}}\left|\tilde{\mathrm{Z}}_{\mathrm{i}}\right|^{2},
\end{aligned}
$$

where $\mathrm{L}_{1}, \mathrm{~L}_{2}$ - the probability ratio for weak and strong signals, respectively; $A_{i 1}=\frac{P_{i}}{P_{1}}-$ the ratio of the average signal power in the $\mathrm{i}$-th and the first channel; $\mathrm{N}_{\mathrm{i}}-$ one-way spectral power density of white noise in the i-th channel; $Z_{i}$ - the result of the coordinated processing of the received signals in the $\mathrm{i}$-th channel; $\mathrm{m}$ is the number of processing channels.

The algorithm of optimal processing (1), (2), which provides detection of the object when it is irradiated by several transmitters, is reduced to the coordinated processing of received echoes, quadratic detection in each processing channel and weight summation of detector outputs of all channels. The weights depend on the signal-to-noise ratio and the spectral noise density in the processing channels.

The block diagram of the detector, which implements the algorithms for detecting the object (1), (2) using the illumination of the object by several transmitters, is shown in Figure 3. As can be seen from Figure 3, when constructing a radar system consisting of one receiving and several transmitting positions, the optimal detector is multichannel. The work of the detector (Det) is reduced to the coordinated processing of echo signals and detection.

The output signals of the coordinated processing devices are equalized by the delay (according to the delay values), which is due to the different distances between the receiving and transmitting positions. The delay-aligned signals are summed with weights $\mathrm{Q}_{\mathrm{k}}$. The values of the coefficients depend on the signal-to-noise ratio in the processing channels.

The signal from the output of the adder (calculated likelihood ratio) is fed to the threshold device, where it is compared with the threshold. The value of the threshold depends on the selected detection criterion (minimum average risk, minimum, Neumann - Pearson, ideal observer, etc.). Depending on whether or not the threshold is exceeded, a decision is made on the presence or absence of a signal.

To evaluate the quality indicators of object detection using several transmitters, we will analyze the nature of fluctuations in the amplitude of the signal reflected by the object. The nature of the echo amplitude fluctuations is determined by the nature of the effective scattering surface fluctuations of the object. Amplitude fluctuations of echo signals for a wide class of objects can be described by Nakagami m-distribution models, logarithmically normal distribution or a set of Johnson distributions. An indicator of the choice of the model of the distribution of amplitude fluctuations is the ratio (3):

$$
\mathrm{k}_{\mathrm{tg}}=\frac{\bar{\sigma}_{\mathrm{tg}}}{\sigma_{\mathrm{tg} \text { med }}},
$$

where $\mathrm{k}_{\mathrm{tg}}$ - the applicability of the model of the distribution of fluctuations in the amplitude of echo signals; $\bar{\sigma}_{\text {tg }}, \sigma_{\text {tg med }}-$ average and median value of the effective scattering surface, respectively. 
Hennadii Khudov et al., International Journal of Emerging Trends in Engineering Research, 8(8), August 2020, 4463 - 4471
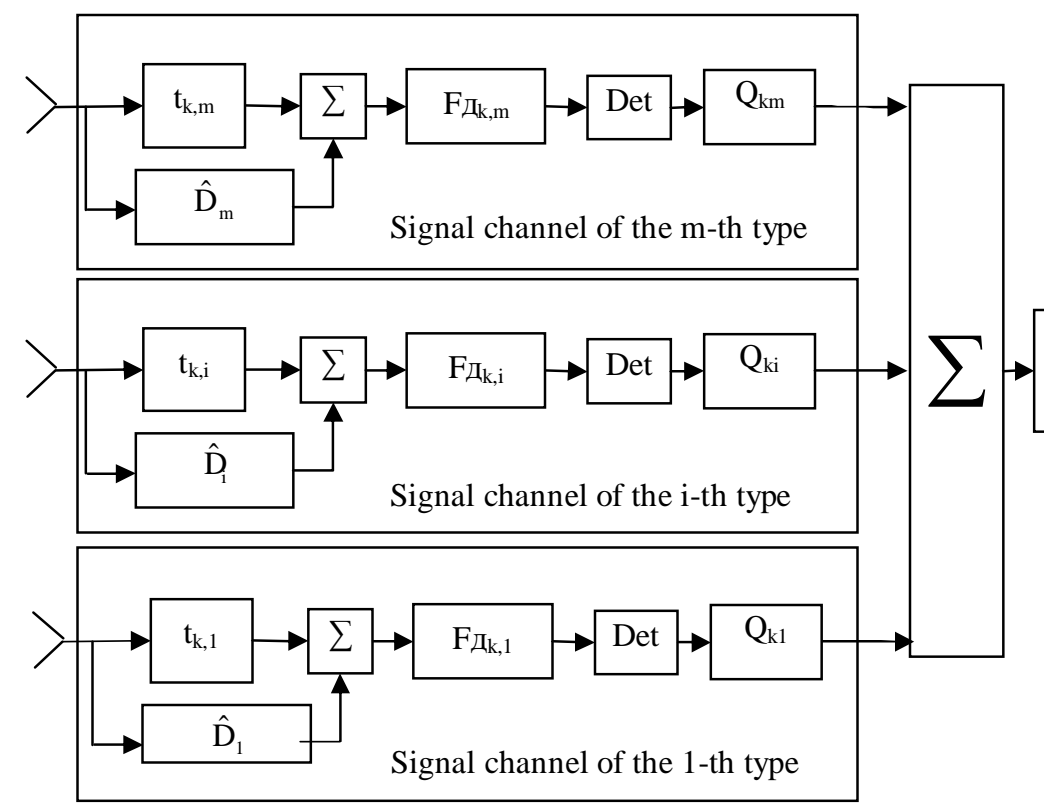

There is a signal

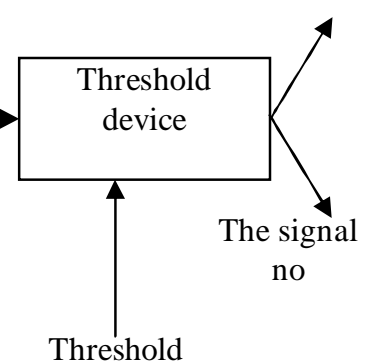

Figure 3: The block diagram of an optimal detector that detects an object using multiple transmitters 
Hennadii Khudov et al., International Journal of Emerging Trends in Engineering Research, 8(8), August 2020, 4463 - 4471

The value corresponds to the Nakagami distribution with $\mathrm{m}=1$ (Rayleigh distribution), corresponds to the Nakagami distribution with $\mathrm{m}=2$, for the values use an approximation of the logarithmically normal distribution model (4):

$$
\mathrm{p}\left(\sigma_{\mathrm{tg}}\right)=\frac{1}{\sigma_{\mathrm{tg}} \sqrt{2 \pi \Theta}} \mathrm{e}^{-\frac{\left(\ln \left(\sigma_{\mathrm{tg}}\right) \overline{\left.\ln \left(\sigma_{\mathrm{tg}}\right)\right)^{2}}\right.}{2 \Theta}} .
$$

When using expression (4), the relationship between the nature of the fluctuations of the effective scattering surface and the distribution parameters is determined by the expression:

$$
\mathrm{k}_{\mathrm{tg}}=\frac{\bar{\sigma}_{\mathrm{tg}}}{\sigma_{\mathrm{tg} \text { med }}}=\mathrm{e}^{\frac{\Theta}{2}} .
$$

The value of the parameter calculated using the methods and algorithms presented in [25]-[26] for a monostatic and bistatic effective scattering surface of small targets (AGM-86C cruise missiles, Taurus KEPD 350) for the frequency of the probing signal corresponding to the operating range of the radar meter range, are shown in table 1 , table 2 .

Table 1: The value of the parameter $\mathrm{k}_{\mathrm{tg}}$ for monostatic effective

\begin{tabular}{|c|c|c|c|c|}
\hline \multirow{2}{*}{$\begin{array}{l}\text { The type of } \\
\text { effective } \\
\text { scattering } \\
\text { surface }\end{array}$} & \multirow[t]{2}{*}{ Polarization } & \multicolumn{3}{|c|}{$\begin{array}{l}\text { Values at an azimuthal } \\
\text { foreshortening, degrees }\end{array}$} \\
\hline & & $0-45$ & $45-135$ & $135-180$ \\
\hline \multicolumn{5}{|c|}{ AGM-86C } \\
\hline \multirow{2}{*}{$\begin{array}{c}\text { Average } \\
\text { effective } \\
\text { scattering } \\
\text { surface }\end{array}$} & horizontal & 11,342 & 10,454 & 10,603 \\
\hline & vertical & 2,609 & 4,894 & 3,024 \\
\hline \multirow{2}{*}{$\begin{array}{c}\text { Median } \\
\text { effective } \\
\text { scattering } \\
\text { surface }\end{array}$} & horizontal & 11,416 & 3,778 & 10,843 \\
\hline & vertical & 2,328 & 1,614 & 3,281 \\
\hline \multirow[t]{2}{*}{$\mathrm{k}_{\mathrm{tg}}$} & horizontal & 0,994 & 2,767 & 0,978 \\
\hline & vertical & 1,121 & 3,032 & 0,922 \\
\hline \multirow[t]{2}{*}{$\overline{\mathrm{k}}_{\mathrm{tg}}$} & horizontal & \multicolumn{3}{|c|}{1,58} \\
\hline & vertical & \multicolumn{3}{|c|}{1,69} \\
\hline \multicolumn{5}{|c|}{ Taurus KEPD 35} \\
\hline \multirow{2}{*}{$\begin{array}{c}\text { Average } \\
\text { effective } \\
\text { scattering } \\
\text { surface }\end{array}$} & horizontal & 13,609 & 7,292 & 5,72 \\
\hline & vertical & 8,582 & 8,299 & 3,318 \\
\hline \multirow{2}{*}{$\begin{array}{c}\text { Median } \\
\text { effective } \\
\text { scattering } \\
\text { surface }\end{array}$} & horizontal & 11,117 & 7,16 & 1,331 \\
\hline & vertical & 4,835 & 4,47 & 3,57 \\
\hline \multirow[t]{2}{*}{$\mathrm{k}_{\mathrm{tg}}$} & horizontal & 1,23 & 1,02 & 4,29 \\
\hline & vertical & 1,78 & 1,86 & 0,93 \\
\hline
\end{tabular}
scattering surface

\begin{tabular}{|c|c|c|}
\hline \multirow{2}{*}{$\overline{\mathrm{k}}_{\mathrm{tg}}$} & horizontal & 2,18 \\
\cline { 2 - 3 } & vertical & 1,52 \\
\hline
\end{tabular}

Table 2: The value of the parameter $\mathrm{k}_{\mathrm{tg}}$ for bistatic effective

\begin{tabular}{|c|c|c|c|c|}
\hline \multirow{2}{*}{$\begin{array}{l}\text { The type of } \\
\text { effective } \\
\text { scattering } \\
\text { surface }\end{array}$} & \multirow[t]{2}{*}{ Polarization } & \multicolumn{3}{|c|}{$\begin{array}{l}\text { Values at an azimuthal } \\
\text { foreshortening, degrees }\end{array}$} \\
\hline & & $0-45$ & $45-135$ & $135-180$ \\
\hline \multicolumn{5}{|c|}{ AGM-86C } \\
\hline \multirow{2}{*}{$\begin{array}{c}\text { Average } \\
\text { effective } \\
\text { scattering } \\
\text { surface }\end{array}$} & horizontal & 3,974 & 1,262 & 19,99 \\
\hline & vertical & 2,818 & 2,636 & 7,061 \\
\hline \multirow{2}{*}{$\begin{array}{c}\text { Median } \\
\text { effective } \\
\text { scattering } \\
\text { surface }\end{array}$} & horizontal & 3,703 & 0,792 & 19,142 \\
\hline & vertical & 2,56 & 2,24 & 7,263 \\
\hline \multirow[t]{2}{*}{$\mathrm{k}_{\mathrm{tg}}$} & horizontal & 1,07 & 1,59 & 1,04 \\
\hline & vertical & 1,1 & 1,17 & 0,97 \\
\hline \multirow[t]{2}{*}{$\overline{\mathrm{k}}_{\mathrm{tg}}$} & horizontal & \multicolumn{3}{|c|}{1,23} \\
\hline & vertical & \multicolumn{3}{|c|}{1,08} \\
\hline \multicolumn{5}{|c|}{ Taurus KEPD 35} \\
\hline \multirow{2}{*}{$\begin{array}{c}\text { Average } \\
\text { effective } \\
\text { scattering } \\
\text { surface }\end{array}$} & horizontal & 13,13 & 2,523 & 35,343 \\
\hline & vertical & 11,297 & 5,931 & 18,358 \\
\hline \multirow{2}{*}{$\begin{array}{c}\text { Median } \\
\text { effective } \\
\text { scattering } \\
\text { surface }\end{array}$} & horizontal & 10,164 & 1,949 & 29,604 \\
\hline & vertical & 8,735 & 4,44 & 14,656 \\
\hline \multirow[t]{2}{*}{$\mathrm{k}_{\mathrm{tg}}$} & horizontal & 1,29 & 1,29 & 1,19 \\
\hline & vertical & 1,29 & 1,34 & 1,25 \\
\hline \multirow[t]{2}{*}{$\overline{\mathrm{k}}_{\mathrm{tg}}$} & horizontal & \multicolumn{3}{|c|}{1,26} \\
\hline & vertical & \multicolumn{3}{|c|}{1,29} \\
\hline
\end{tabular}
scattering surface

From the analysis of the average values of the parameter $\overline{\mathrm{k}}_{\mathrm{tg}}$ (table 1, table 2) it is seen that for the monostatic effective scattering surface the parameter values change within 1.52-2.18, and for the bistatic effective scattering surface the parameter value changes within 1.08-1.29.

To assess the quality of detection of objects, which are listed in table 1 and table 2, taking into account the nature of fluctuations in the amplitude of echo signals, it is necessary:

- find the analytical expression of the signal-to-noise ratio at the output of the coordinated processing system for a signal with an amplitude multiplier that satisfies the logarithmic-normal distribution (4); 
- find the analytical expression of the dependence of the probability of correct detection on the signal-to-noise ratio and construct detection curves.

To simplify the task of finding an analytical expression to assess the quality of detection of objects, which are listed in table 1, table 2, you can use the following features:

- the interval of change of parameter values $\overline{\mathrm{k}}_{\mathrm{tg}}$ for the bistatic effective surface $(0,92-1,29)$ includes the value $\mathrm{k}_{\mathrm{tg}}=1,18$ corresponding to the Nakagami distribution with the parameter $\mathrm{m}=2$;

- the interval of change of parameter values $\overline{\mathrm{k}}_{\mathrm{tg}}$ for the monostatic effective scattering surface $(1,42-2,18)$ includes the value $\mathrm{k}_{\mathrm{tg}}=1,44$ corresponding to the Nakagami distribution with $\mathrm{m}=1$.

The presence of amplitude fluctuations leads to a deterioration in the quality of target detection (with values of the probability of correct detection greater than 0.5 ) relative to the case when the amplitude fluctuations are absent. Given the above, a comparative assessment of object detection quality indicators using bistatic and monostatic effective scattering surfaces can be made using the Nakagami distribution with parameters $\mathrm{m}=2$ and $\mathrm{m}=1$, respectively.

For a signal with a random amplitude with a Nakagami distribution at $\mathrm{m}=1$ (corresponding to the Rayleigh distribution), the conditional probability of correct detection is determined by the expression (6):

$$
\mathrm{D}=\mathrm{F}^{\frac{1}{1+\frac{\mathrm{q}^{2}}{2}}}
$$

where $\mathrm{D}$ is the conditional probability of correct detection; $\mathrm{F}$ conditional probability of false alarm; q - signal-to-noise ratio at the input of the threshold device.

For a signal with a random amplitude with Nakagami distribution at $\mathrm{m}=2$, the conditional probability of correct detection is determined by the expression (7):

$$
\mathrm{D}=\left[1+\frac{\frac{\mathrm{q}^{2}}{4}}{\left(1+\frac{\mathrm{q}^{2}}{4}\right)^{2}} \ln \left(\frac{1}{\mathrm{~F}}\right)\right] \mathrm{F}^{\frac{1}{1+\frac{\mathrm{q}^{2}}{4}}} \text {. }
$$

In the case of incoherent channel aggregation, provided that the signal-to-noise ratio in all channels is the same and there is no interchannel correlation of complex amplitudes (independent fluctuations in the intensity of spatially incoherent signals in the channels), the probability of correct detection is determined by (8):

$$
\mathrm{D}=\mathrm{e}^{-\frac{\mathrm{u}_{0}}{2\left(1+\tilde{\tilde{q}}^{2}\right)}} \sum_{\mathrm{k}=0}^{\mathrm{m}-1} \frac{\left(\frac{\mathrm{u}_{0}}{2}\right)^{\mathrm{k}}}{\mathrm{k} !\left(1+\tilde{\mathrm{q}}^{2}\right)^{\mathrm{k}}},
$$

where $\mathrm{m}$ is the number of incoherent channels to be merged; $\tilde{\mathrm{q}}$ - the average signal-to-noise ratio at the output of the processing channel (the same for all channels); $\mathrm{u}_{0}$ normalized threshold level, which depends on the probability of false alarm and is determined from the expression (9):

$$
\mathrm{F}=\mathrm{e}^{-\frac{\mathrm{u}_{0}}{2}} \sum_{\mathrm{k}=0}^{\mathrm{m}-1} \frac{\left(\frac{\mathrm{u}_{0}}{2}\right)^{\mathrm{k}}}{\mathrm{k} !} .
$$

In Figure 4 shows the characteristics of detection, which are built on expressions (6), (7), (8). The curve 1 and the curve 2 correspond to object detection using a monostatic effective scattering surface and a bistatically effective scattering surface, respectively. The shift of curve 2 to the left relative to curve 1 is explained by differences in the nature of fluctuations in the intensity of echo signals in monostatic and bistatic modes. The curves 3, 4, 5 correspond to the detection of the object in the incoherent combination of 2, 3 and 4 detection channels, respectively, provided that the signal-to-noise ratio in these channels is the same.

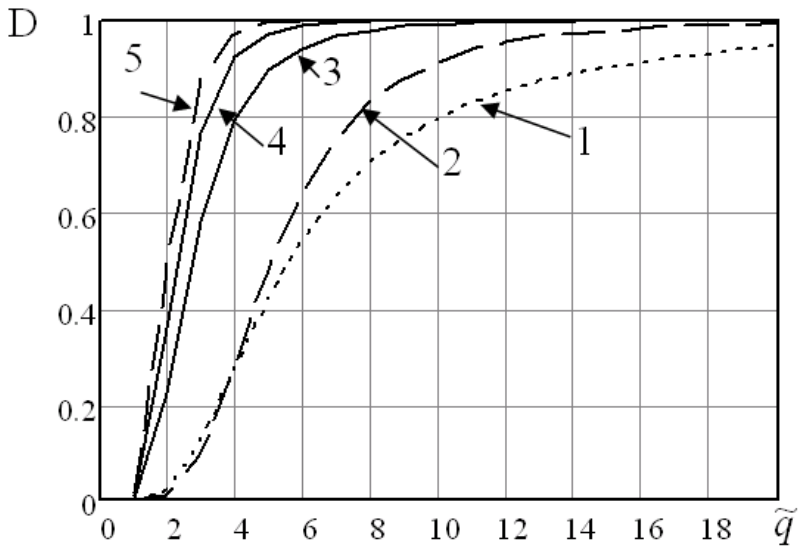

Figure 4: The characteristics of object detection in the channels for the probability of false alarm $\mathrm{F}=10^{-5}$ : 1 - using a monostatic effective defraction surface; 2 - using a bistatically effective scattering surface; 3 - in case of incoherent combination of 2 channels; 4 - in case of incoherent combination of 3 channels; 5 - in case of incoherent combination of 4 channels.

From the analysis of the detection characteristics shown in Figure 4, it is seen that the transition from single-channel object detection (curves 1, 2) to object detection with incoherent combination of two channels (curve 3 ) leads to a significant shift of the detection characteristics to the left. A further increase in the number of channels that are combined incoherently (curves 4,5 ) does not lead to a significant shift 
in the detection characteristics to the left compared to the detection characteristics when combining two channels (curve 3).

In Figure 5 shows the dependence of the energy gain in the desired signal-to-noise ratio in each processing channel to ensure quality indicators of target detection, with incoherent combination of channels on the number of combined channels.

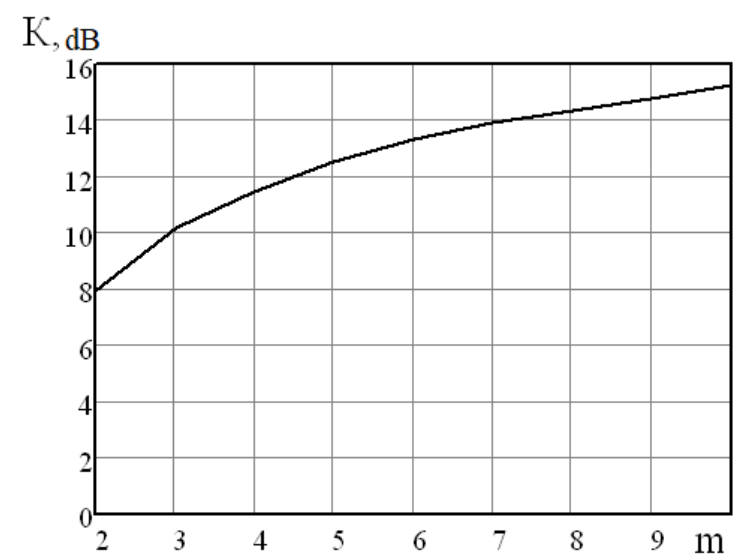

Figure 5: The gain in the signal-to-noise ratio in the channels when they are incoherently combined with respect to the signal-to-noise value in a single-position channel that uses a monostatic effective scattering surface (for detection quality indicators $\mathrm{D}=0,8, \mathrm{~F}=10^{-5}$ )

The gain in Figure 5 shows the relative signal / noise value required to detect an object in a channel that uses a single-position effective scattering surface (10):

$$
\mathrm{K}_{\mathrm{m}}=20 \lg \left(\frac{\mathrm{q}_{1}}{\tilde{\mathrm{q}}_{\mathrm{m}}}\right),
$$

where $\mathrm{K}_{\mathrm{m}}$ - the gain in the signal / noise ratio in the $\mathrm{m}$-th channel relative to the channel with the signal-to-noise ratio $\mathrm{q}_{1} ; \mathrm{q}_{1}$ - the signal-to-noise ratio in the channel, which uses a monostatic effective scattering surface, which is required to ensure the specified quality indicators of target detection without the use of additional channels; - the signal-to-noise ratio in the $\mathrm{m}$-th channel, which is required to ensure the specified target detection rates in case of incoherent combination of $\mathrm{m}$ channel.

From the analysis of the dependence of the gain in the signal-to-noise ratio shown in Figure 5, it is seen that the combination of two channels (monostatic and bistatic) provides a gain of $8 \mathrm{~dB}$. Adding a third channel increases the gain by only $2 \mathrm{~dB}$. A further increase in the number of merged channels results in an increase in gain of less than $2 \mathrm{~dB}$ for each added channel. Therefore, according to the criterion of efficiency-cost, the most effective is the combination of two, maximum three channels (one-position and one or two bistatic).
In Figure 6 shows the dependence of the gain in the signal-to-noise ratio in the processing channels on a given probability of correct detection in the incoherent combination of different numbers of channels.

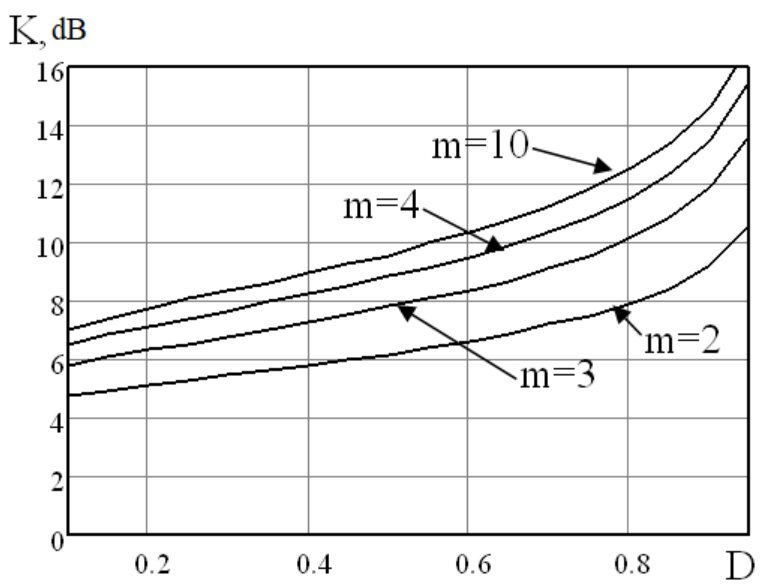

Figure 6: The gain in the signal-to-noise ratio for incoherent combination of $m$ channels relative to the signal-to-noise value in a single-position channel that uses a monostatic effective scattering surface (for $\mathrm{F}=10^{-5}$ )

From the analysis of the curves shown in Figure 6, it is seen that as the probability of correct detection increases, the gain in signal / noise ratio increases. The gain gain in the signal-to-noise ratio decreases at $m>3$, which confirms the inexpediency of incoherent combination of more than three channels.

\section{CONCLUSION}

Thus, the analysis shows that the incoherent combination of single-position and spaced processing channels provides the ability to detect small air objects in the meter range of wavelengths with indicators of detection quality and reducing the signal-to-noise ratio in each channel by $8 \mathrm{~dB}$ compared to the case when the detection of an object with the same quality indicators is carried out independently by each channel.

It is shown that according to the criterion of efficiency-cost, the use of more than two channels (one monostatic and one bistatic) to ensure energy gain in the detection of objects is impractical.

In further studies to determine the impact of energy gain on the parameters of the detection zone of small objects when combining the modes of single-position and spaced reception, it is necessary to analyze the dependence of the signal-to-noise ratio on the geometry of such a system

\section{REFERENCES}

1. M. Banasik, Armed Forces As The Russian Federation's Strategic Tool, Journal on Baltic Security, № $5(2), \quad$ 2019, pp. 1-12. DOI: https://doi.org/10.2478/jobs-2019-0008. 
2. C. Pascarelli, M. Marra, G. Avanzini, and A. Corallo Environment for Planning Unmanned Aerial Vehicles Operations Aerospace, 2019, 6 (5), 51. DOI: https://doi.org/10.3390/aerospace6050051.

3. H. Khudov, S. Yarosh, V. Savran, A. Zvonko, A. Shcherba, P. Arkushenko The Technique of Research on the Development of Radar Methods of Small Air Objects Detection, International Journal of Emerging Trends in Engineering Research, Vol. 8. № 7, 2020, pp. 3708-3715.

DOI: https://doi.org/10.30534/ijeter/2020/132872020.

4. O. Barabash, N. Dakhno, H. Shevchenko, and T. Majsak Dynamic Models of Decision Support Systems for Controlling UAV by Two-Step Variational-Gradient Method, Proceedings of 2017 IEEE 4th International Conference "Actual Problems of Unmanned Aerial Vehicles Developments (APUAVD)", October 17-19, 2017, Kyiv, Ukraine. pp. 108-111. DOI:https://doi.org/10.1109/APUAVD.2017.8308787

5. H. Khudov, R. Khudov, I. Khizhnyak, V. Loza, T. Kravets, S. Kibitkin Estimation of the Kullback-Leibler Divergence for Canny Edge Detector of Optoelectronic Images Segmentation, International Journal of Emerging Trends in Engineering Research, Vol. 8. № 7, 2020, pp. 3927-3934. DOI: https://doi.org/10.30534/ijeter/2020/162872020.

6. H. Khudov, I. Ruban, O. Makoveichuk, H. Pevtsov, V. Khudov, I. Khizhnyak, S. Fryz, V. Podlipaiev, Y. Polonskyi, and R. Khudov. Development of methods for determining the contours of objects for a complex structured color image based on the ant colony optimization algorithm, Eureka: Physics and Engineering, № 1, 2020, pp. 34-47.

DOI: https://doi.org/10.21303/2461-4262.2020.001108.

7. G. V. Khudov, Features of optimization of two-alternative decisions by joint search and detection of objects. Problemy Upravleniya I Informatiki (Avtomatika), 2003, № 5, pp. 51-59.

8. V. Lishchenko, H. Khudov, V. Tiutiunnyk, V._Kuprii, F._Zots, and G._Misiyuk. The Method of Increasing the Detection Range of Unmanned Aerial Vehicles In Multiradar Systems Based on Surveillance Radars, in 2019 IEEE 39th International Conference on Electronics and Nanotechnology (ELNANO), 2019. P. 559-562. DOI: https://doi.org/10.1109/ELNANO.2019.8783263.

9. H. Khudov, A. Zvonko, S. Kovalevskyi, V. Lishchenko, and F. Zots. Method for the detection of smallsized air objects by observational radars, Eastern-European Journal of Enterprise Technologies, № 2/9 (92), 2018, pp. 61-68.

DOI: https://doi.org/10.15587/1729-4061.2018.126509.

10. H. Khudov, I. Khizhnyak, V. Koval, V. Maliuha, A. Zvonko, V. Yunda, V. Nagachevskyi, and V. Berezanskyi The Efficiency Estimation Method of Joint Search and Detection of Objects for Surveillance Technical Systems, International Journal of Emerging Trends in Engineering Research, Vol. 8. № 3, 2020, pp. 813-819.

DOI: https://doi.org/10.30534/ijeter/2020/34832020.

11. I. Ruban, H. Khudov, V. Lishchenko, A. Zvonko, S. Glukhov, I. Khizhnyak, V. Maliuha, Y. Polonskyi, R. Kushpeta, The Calculating Effectiveness Increasing of Detecting Air Objects by Combining Surveillance Radars into The Coherent System, International Journal of Emerging Trends in Engineering Research, Vol. 8., № 4, 2020, pp. 1295-1301.

DOI: https://doi.org/10.30534/ijeter/2020/58842020.

12. V. Lishchenko, T. Kalimulin, I. Khizhnyak, and H. Khudov, The method of the organization coordinated work for air surveillance in MIMO radar, Paper presented at the 2018 International Conference on Information and Telecommunication Technologies and Radio Electronics, UkrMiCo, 2018 - Proceeding.

DOI: https://doi.org/doi:10.1109/ UkrMiCo43733. 2018.9047560.

13. H. Khudov, A. Fedorov, D. Holovniak, and G. Misiyuk. Improving the Efficiency of Radar Control of Airspace with the Multilateration System Use, in Intern. Scient.-Pract. Conf. Problems of Infocommunications. Science and Technology (PIC S\&T), 2018, pp. 680-684. DOI: https://doi.org/10.1109/infocommst.2018.8632141.

14. H. Khudov, S. Glukhov, O. Maistrenko, A. Fedorov, A. Andriienko, O. Koplik, The Method of ADS-B Receiver Systems Synchronization Using MLAT Technologies in the Course of Radar Control of Air Environment, International Journal of Emerging Trends in Engineering Research, Vol. 8. № 5, 2020, pp. 1946-1951.

DOI: https://doi.org/10.30534/ijeter/2020/78852020.

15. V. Lishchenko, H. Khudov, B. Lisogorsky, O. Baranik, D. Holovniak, and O. Serdjuk The MIMO System on Based Existing Mechanical Rotation Radars with Wide Surveillance Area, in 2020 IEEE 40th International Conference on Electronics and Nanotechnology (ELNANO), 2020. P. 625-628. DOI: https://doi.org/10.1109/ELNANO.50318.2020.90887463

16. H. Khudov, V. Lishchenko, B. Lanetskii, V. Lukianchuk, S. Stetsiv, and I. Kravchenko The coherent signals processing method in the multiradar system of the same type two-coordinate surveillance radars with mechanical azimuthal rotation, International Journal of Emerging Trends in Engineering Research, Vol. 8. № 6, 2020, pp. 2624-2630.

DOI: https://doi.org/10.30534/ijeter/2020/66862020.

17. H. Khudov, V. Lishchenko, H. Hyshko, Y. Polonskyi, I. Khizhnyak, B. Riabukha, The MIMO Surveillance Radars System with High Accuracy Finding 2D Coordinates, International Journal of Emerging Trends in Engineering Research, Vol. 8. № 5, 2020, pp. 2026-2030.

DOI: https://doi.org/10.30534/ijeter/2020/91852020.

18. H. Khudov, A. Zvonko, I. Khizhnyak, V. Shulezko, V. Khlopiachyi, V. Chepurnyi, and I. Yuzova. The 
Synthesis of the Optimal Decision Rule for Detecting an Object in a Joint Search and Detection of Objects by the Criterion of Maximum Likelihood, International Journal of Emerging Trends in Engineering Research, № 8(2), 2020, pp. 520-524.

DOI: https://doi.org/10.30534/ijeter/2020/40822020.

19. H. Khudov, I. Khizhnyak, I. Yuzova, O. Baranik, G. Semiv, S. Bondarenko, and O. Tytarenko. The Optimization Technique for Joint Discrete Search and Detection of Observation Objects, International Journal of Emerging Trends in Engineering Research, № 8(2), 2020, pp. 533-538.

DOI: https://doi.org/10.30534/ijeter/2020/42822020.

20. H. Khudov， S. Kovalevskyi， A. Irkha, V. Lishchenko, O. Serdiuk and F. Zots, The Proposals for Synchronization Positions of MIMO Radar System on the Basis of Surveillance Radars, in Intern. Scient.-Pract. Conf. Problems of Infocommunications. Science and Technology (PIC S\&T), 2019, pp. 547-551. DOI: https://doi.org/10.1109/PICST47496.2019.9061284.

21. V. Lishchenko, V. Chaliy, H. Khudov, and A. Zvonko. Proposals for Improving of Air Surveillance Informativity in MIMO Radar Systems Based on Two-Dimensional Radars, in Intern. Scient.-Pract. Conf. Problems of Infocommunications. Science and Technology (PIC S\&T), 2018, pp. 153-156.

DOI: https://doi.org/10.1109/infocommst.2018.8632052.

22. H. Khudov, I. Khizhnyak, F. Zots, G. Misiyuk, and O. Serdiuk. The Bayes Rule of Decision Making in Joint Optimization of Search and Detection of Objects in Technical Systems, IJETER, № 8(1), 2020, pp. 7-12. DOI: https://doi.org/10.30534/ijeter/2020/02812020.

23. H. Khudov, A. Fedorov, D. Holovniak, and G. Misiyuk, Method of Radar Adjustment with Automatic Dependent Surveillance Technology Use, in Intern. Scient.-Pract. Conf. Problems of Infocommunications. Science and Technology (PIC S\&T), 2019, pp. 402-406. DOI:https://doi.org/10.1109/PICST47496.2019.9061245

24. I. Ruban, H. Khudov, O. Makoveichuk, I. Khizhnyak, N. Lukova-Chuiko, G. Pevtsov, Y. Sheviakov, I. Yuzova, Y. Drob, and O. Tytarenko, Method for determining elements of urban infrastructure objects based on the results from air monitoring, Eastern-European Journal of Enterprise Technologies, № 4/9 (100), 2019, pp. $52-61$.

DOI: https://doi.org/10.15587/1729-4061.2019.174576.

25. A. Maslovskiy, V. Vasylets, S. Nechitaylo, O. Sukharevsky Method of radar masking of the ground based military equipment objects, Telecommunications and Radio Engineering, № 78(1)б 2019, pp. 47-58.

DOI:https://doi.org/10.1615/TelecomRadEng.v78.i1.60.

26. V. Vasilets, S. Nechitaylo, O.Sukharevsky, V. Orlenko

Electromagnetic Wave Scattering by Aerial and
Ground Radar Objects. Edited by Oleg Sukharevsky. CRC Press, 2014, 301 p. 